\title{
Tensile Strength of PHBV/Natural Rubber Latex Mixtures
}

\author{
Sarunya Promkotra ${ }^{1}$, Tawiwan Kangsadan ${ }^{2}$ \\ ${ }^{1}$ Department of Geotechnology, Faculty of Technology, Khon Kaen University, Khon Kaen 40002, Thailand \\ ${ }^{2}$ Chemical and Process Engineering Program, Department of Mechanical and Process Engineering, The Sirindhorn International Thai- \\ German Graduate School of Engineering (TGGS), King Mongkut's University of Technology North Bangkok (KMUTNB), Bangkok 10800, \\ Thailand
}

\begin{abstract}
A polyhydroxybutyrate-co-hydroxyvalerate (PHBV) is mingled with natural rubber latex (R) to develop its mechanical property of the blend. Normally, substantial effects of the PHBV are hard, fragile, and inelastic, whereas the natural rubber is represented itself as very high elastic matter. The mixtures between the PHBV and natural rubber latex $(\mathrm{R})$ are considered in different proportions. The PHBV solutions (w/v) are defined suitability at $1 \%(\mathrm{P} 1), 2 \%$ $(\mathrm{P} 2)$, and 3\% (P3). Their liquid mixtures of the PHBV to natural rubber latex (P:R) are fabricated the blended films in three different ratios of 2:3, 1:1 and 3:2, respectively. The PHBV blended films are characterized the crystallinity form by x-ray diffractometry (XRD), which are appeared their identity crystals at 13.30 and 16.68 degree (2 $\theta$ ). Mechanical characterizations of the blends are examined by a universal testing machine (UTM). The average elastic moduli of P1, P2, and P3 mixtures are indicated as 773, 955, and 1,007 kPa, respectively. Their tensile strengths, similarly to elastic moduli, enhance with the PHBV concentrations. The effects of mechanical behaviors and crystallinity reveal that the PHBV blends can be improved their properties by more flexible with natural rubber latex.
\end{abstract}

\section{Introduction}

A bioplastic-based material of polyhydroxybutyrate-cohydroxyvalerate (PHBV) is a member of the polyhydroxylalkanoates (PHAs) which are produced by microbial activity on sugar-based system [1-3]. This biopolymer is presented itself as the biodegradable polymer and aliphatic polyesters because of naturally synthesized materials from renewable supplies. According to the study of Kuntanoo and others (2015) [45], the PHBV chains additionally reveal crystalline conformations and the co-monomer dispersion specifies statistically arbitrary. The main copolymer consists of two copolymers, 3HV (hydroxyvalerate) and 3HB (hydroxybutyrate), which their properties depend on the HV specialty. Its member, PHBV, appears principally concerns by excessively rigid, fragile, and absence of enhanced mechanical behaviors. These properties are required for advanced applications. Mechanical property is one of some modifications to improve PHBV, for example chemical modification or physical blending. The latter is desired because of rapid, simple, and lowexpense functioning performances [4].

To improve the properties of PHBV, blended materials have been chosen and developed. Natural rubber, the solid form of creamy latex from the heveabrasiliensis tree, is one of the selected materials [1]. The majorcomposition is composed of cis-poly (isoprene)-isoprene monomer. Furthermore, the advantages related to the blends provide the distinctive physical properties for contributing extensive industrial purpose. Elasticity of natural rubber can prove the exceptional mechanical properties and be influenced to acquire the rubber like the mixture [2]. Thus, the PHBV copolymer and natural rubber are followed to improve novel mechanical properties of materials [3].

\section{Experimental Details}

\subsection{Materials}

Composite polymers of this research focus on PHBV and natural rubber latex. The PHBV granular commercial grade is made by an industrial manufacturing, Tianan Biologic Material Co., China. This PHBV dissolves in chloroform solution. Another blended material, natural rubber latex, accomplishes to mix with PHBV in solution. The Office of the Rubber Replanting Aid Fund, Khon Kean province, Thailand, contributes fresh natural rubber latex, planted in the northeastern Thailand.

\subsection{Polyhydroxybutyrate-co-hydroxyvalerate (PHBV)}

The PHBV includes nucleating agent and antioxidant. Its shape obviously presents ina yellowish-white tablet with a solid density and thehydroxyvalerate (HV) content of $1.24 \mathrm{~g} / \mathrm{cm}^{3}$ and $3 \mathrm{~mol} \%$, respectively. According to the initial raw material of PHBV, polyhydroxyalkanoates

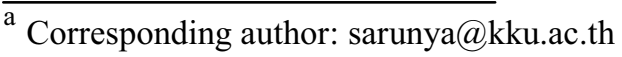


(PHAs), its concentration in chloroform is prepared at $1 \%$, $2 \%$, and $3 \% \mathrm{w} / \mathrm{v}$, by controlling the dissolution temperature at $65-70^{\circ} \mathrm{C}$ inroughly $4 \mathrm{hr}$. Subsequently, separately solution in each concentration is mixed with fresh natural rubber latex (creamy liquid).

\subsection{Natural Rubber Latex}

The tree (heveabrasiliensis) gives openly natural rubber latex for the blend. Chemical constituents of this natural rubber latex are composed of cis-1,4-polyisoprene (rubber particles), water, protein, sterol glycosides, resins, ash, and sugars in the range of $35-42,58-60,2-3,0.1-0.5$, $2.5-3.5,0.5-1.0$, and $1.0-2.0 \%$, respectively. The liquid latex is mixedwith PHBV solution.

\subsection{Blend Preparation}

The blends consist of PHBV solution (P) at concentration of 1,2 , and $3 \% \mathrm{w} / \mathrm{v}$ and the natural rubber latex (R). Selection proportions of the mixture ratio between PHBV to the latex $(\mathrm{P}: \mathrm{R})$ are $4: 6,5: 5$, and also $6: 4$ (or $2: 3,1: 1$, $3: 2$ ) (Table 1). Blending occurs under extrusion casting at $65-70{ }^{\circ} \mathrm{C}$, mixing for $1 \mathrm{hr}$, and drying for 3 days at $70{ }^{\circ} \mathrm{C}$ in an oven. A final product is a blend film with $2 \mathrm{~mm}$ thick.

Table 1. Proportions of blended mixtures between PHBV (P) and natural rubber latex $(\mathrm{R})$.

\begin{tabular}{|c|c|c|c|}
\hline Porportion of the Blends (PHBV to Natural Rubber, P:R) \\
\hline \multirow{3}{*}{$\begin{array}{c}\text { PHBV } \\
1: 0\end{array}$} & \multicolumn{3}{|c|}{$1 \% \mathrm{w} / \mathrm{v}$ PHBV $\left(\mathrm{P}_{1}\right)$} \\
\cline { 2 - 4 } & $6: 4$ & $5: 5$ & $4: 6$ \\
\cline { 2 - 4 } & $\mathrm{P}_{1} 3: \mathrm{R} 2$ & $\mathrm{P}_{1} 1: \mathrm{R} 1$ & $\mathrm{P}_{1} 2: \mathrm{R} 3$ \\
\hline \multirow{5}{*}{$2 \% \mathrm{w} / \mathrm{v} \mathrm{PHBV}\left(\mathrm{P}_{2}\right)$} \\
\cline { 2 - 4 } & $6: 4$ & $5: 5$ & $4: 6$ \\
\cline { 2 - 4 } & $\mathrm{P}_{2} 3: \mathrm{R} 2$ & $\mathrm{P}_{2} 1: \mathrm{R} 1$ & $\mathrm{P}_{2} 2: 3$ \\
\cline { 2 - 4 } $3 \% \mathrm{w} / \mathrm{v}$ PHV $\left(\mathrm{P}_{3}\right)$ \\
\hline \multirow{3}{*}{ Natural Rubber $0: 1$} & $6: 4$ & $5: 5$ & $4: 6$ \\
\cline { 2 - 4 } & $\mathrm{P}_{3} 3: \mathrm{R} 2$ & $\mathrm{P}_{3} 1: \mathrm{R} 1$ & $\mathrm{P}_{3} 2: \mathrm{R} 3$ \\
\hline
\end{tabular}

\subsection{X-ray Diffractometry (XRD)}

Crystallinity characteristics of the blends are signified by $\mathrm{x}$-ray diffractometry (XRD), Monochromatic $\mathrm{Cu}-\mathrm{K}_{\alpha}$ radiation (wavelength $=1.5406 \AA$ ), D8 Bruker x-ray diffractometer. Diffraction angle $(2 \theta)$ is defined through the sample area of $4-40^{\circ}$. The operation circumstances are counting the step interval of 0.02 and step time of 0.5 degree/min. Crystallinity of the blended films is quantified following the method of Nara \& Komiya (1983) [6]. The results from the diffractograms of each sample are examined and obtained $d$-spacing and relative intensity [7-8].

\subsection{Universal Testing Machine (UTM)}

Mechanical examination of the blend films is followed under Universal Testing Machine (UTM, model 5567A, Instron, Norwood, MA). Dumbbell-shaped specimens are clamped with pneumatic grips and operated a crosshead speed of $100 \mathrm{~mm} / \mathrm{min}$. The "Die C"-shape depends upon
ASTM D 412 with 115 mm length, and a narrow section of $33 \mathrm{~mm}$ long. This condition arranges a gauge length (benchmark) of $25 \mathrm{~mm}$ long and a gauge width of 6 $\mathrm{mm}$.Increasing load capacity is gradually apply to specimens every two Newton, as shown in Fig.1. The experimental lab tests under the UTM of tensions between loads and extension of specimens are presented in the same plot. Each curve change depends upon the development of a load carrying capacity related to the greatest limit state.
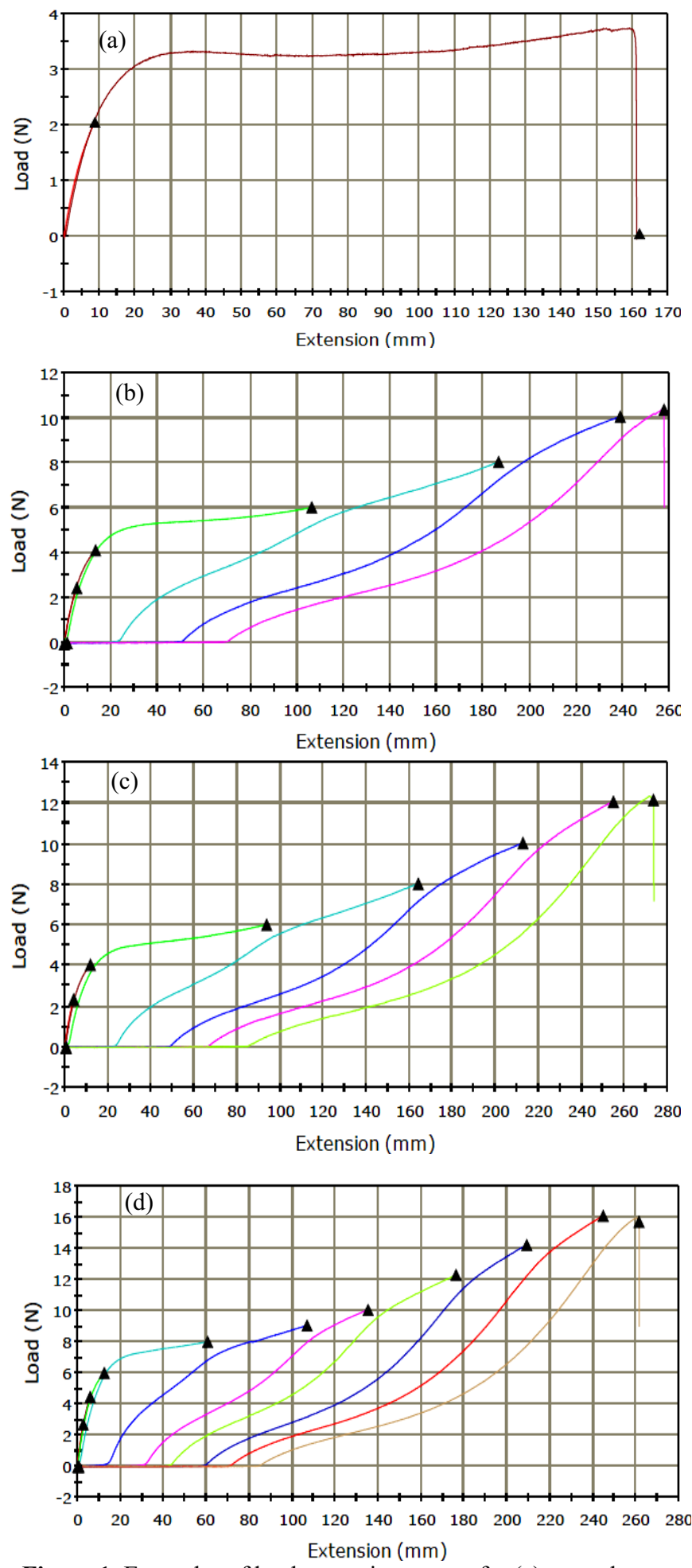

Figure 1. Examples of load-extension curves for (a) natural rubber, (b) $\mathrm{P}_{1} 3: R 2$, (c) $\mathrm{P}_{2} 3: \mathrm{R} 2$, and (d) $\mathrm{P}_{3} 3: \mathrm{R} 2$. 


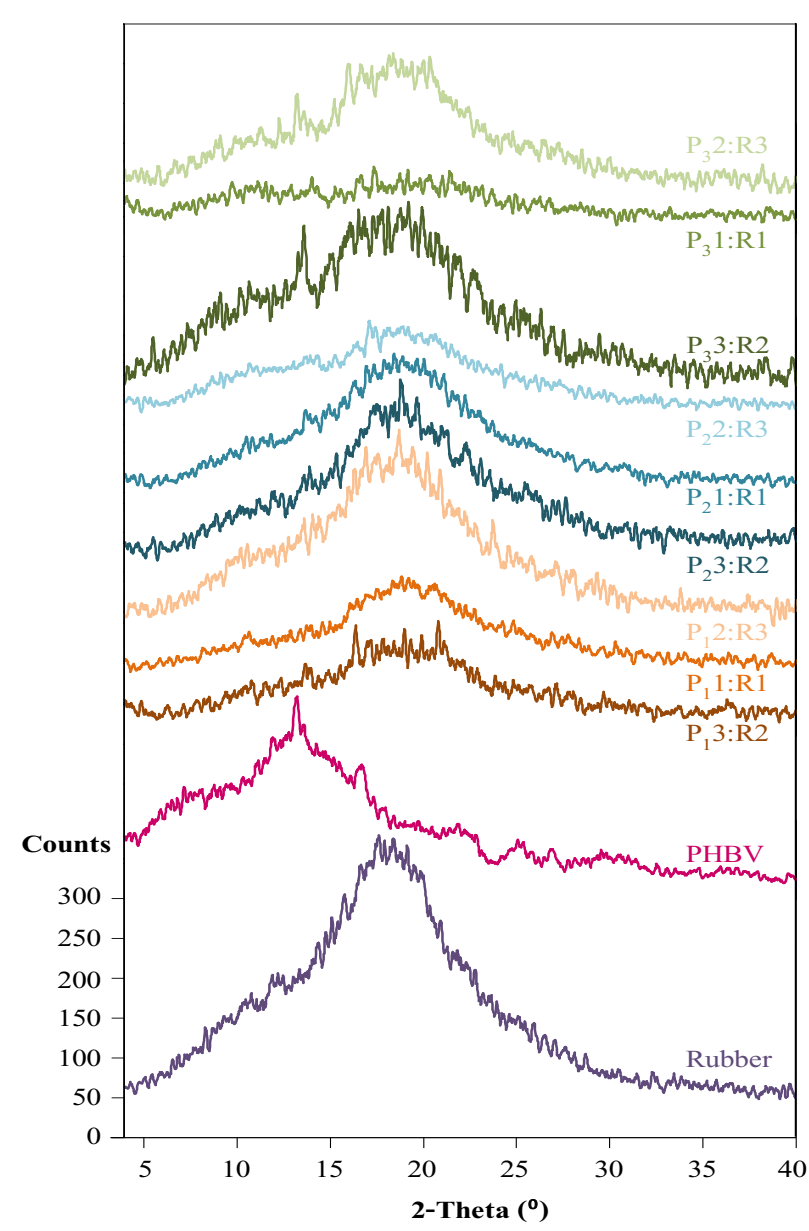

Figure 2. X-ray diffractograms of $P H B V$, natural rubber, and the blended films in three different ratios (P:R) of $2: 3,1: 1$ and $3: 2$ (corresponding to Table 1).

\section{Results and Discussion}

\subsection{Crystallization}

The diffractograms (XRD) of PHBV, natural rubber, and all mixtures are appeared in Fig.2. Their characteristics are obviously distinctive parts with highly crystal peaks of PHBV and also amorphous broad peaks of the natural rubber because of the difference of both chemical structures. The PHBV blends are existed their identity crystals (20) at 13.30 and 16.68 degree. Additionally, the diffraction patterns of PHBV are still found other crystal peaks at the angles of 13.53, 16.94, 22.70, 25.5127 .07 , and 37.16 degree. However, broad peaks always exist for amorphous materials-natural rubber. Crystallinity of the $3 \% \mathrm{w} / \mathrm{v}$ PHBV $\left(\mathrm{P}_{3} 3: \mathrm{R} 2\right)$ are highly found more than the lower PHBV concentration $(1-2 \% \mathrm{w} / \mathrm{v})$.

\subsection{Tensile Modulus on Universal Testing Machine (UTM)}

According to the load-extension results, the analytical computations can refer to the tensile stress and tensile strain scheme, as indicated in Fig.3. Mechanical results of all samples are accomplished in Table 2, which is no data for the brittle PHBV specimens. The mixtures under the
$1 \%$ and $2 \% \mathrm{w} / \mathrm{v}$ PHBV are found several voids in the texture. Therefore, they are no linerily unique development of their tensile properties, but the $3 \% \mathrm{w} / \mathrm{v}$ PHBV blends. For the linear trend of the $3 \% \mathrm{w} / \mathrm{v}$ PHBV, their moduliarise with increasing the PHBV portion (Fig. 4). The higher crystallinity of PHBV mixtures, the better tensile strength.

Table 2. Mechanical results of the mixtures.

\begin{tabular}{|c|c|c|c|}
\hline Category & \multicolumn{3}{|c|}{$1 \% \mathrm{w} / \mathrm{v}$ PHBV $\left(\mathrm{P}_{1}\right)$} \\
\hline PHBV: Rubber & $\mathrm{P}_{1} 3: \mathrm{R} 2$ & $\mathrm{P}_{1} 1: \mathrm{R} 1$ & $\mathrm{P}_{1} 2: \mathrm{R} 3$ \\
\hline Tensile Strength $(\mathrm{kPa})$ & 577 & 537 & 448 \\
\hline Tensile Modulus $(\mathrm{kPa})$ & 755 & 861 & 704 \\
\hline Average Modulus (kPa) & \multicolumn{3}{|c|}{773} \\
\hline & \multicolumn{3}{|c|}{$2 \% \mathrm{w} / \mathrm{v}$ PHBV $\left(\mathrm{P}_{2}\right)$} \\
\hline PHBV: Rubber & $\mathrm{P}_{2} 3: \mathrm{R} 2$ & $\mathrm{P}_{2} 1: \mathrm{R} 1$ & $\mathrm{P}_{2} 2: 3$ \\
\hline Tensile Strength $(\mathrm{kPa})$ & 685 & 694 & 607 \\
\hline Tensile Modulus $(\mathrm{kPa})$ & 887 & 966 & 1,013 \\
\hline Average Modulus (kPa) & \multicolumn{3}{|c|}{955} \\
\hline & \multicolumn{3}{|c|}{$3 \% \mathrm{w} / \mathrm{v}$ PHBV $\left(\mathrm{P}_{3}\right)$} \\
\hline PHBV: Rubber & $\mathrm{P}_{3} 3: \mathrm{R} 2$ & $\mathrm{P}_{3} 1: \mathrm{R} 1$ & $\mathrm{P}_{3} 2: \mathrm{R} 3$ \\
\hline Tensile Strength $(\mathrm{kPa})$ & 894 & 597 & 447 \\
\hline Tensile Modulus $(\mathrm{kPa})$ & 1,511 & 886 & 626 \\
\hline Average Modulus (kPa) & \multicolumn{3}{|c|}{1,007} \\
\hline & \multicolumn{3}{|c|}{ Rubber (R) } \\
\hline Tensile Strength $(\mathrm{kPa})$ & \multicolumn{3}{|c|}{335} \\
\hline Tensile Modulus $(\mathrm{kPa})$ & \multicolumn{3}{|c|}{740} \\
\hline
\end{tabular}

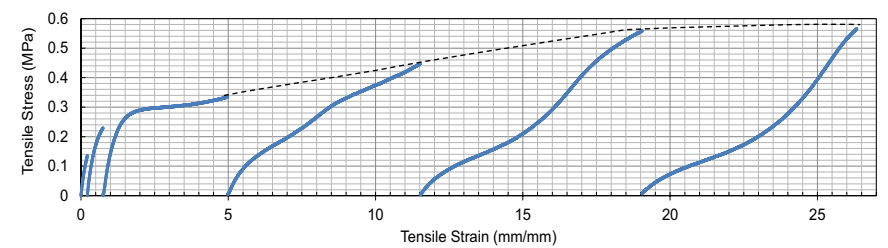

Figure 3. Plots of tensile stress and tensile strain $\left(\mathrm{P}_{1}=1 \% \mathrm{PHBV}, \mathrm{P}_{1} 3=\right.$ $1 \%$ PHBVin $60 \%$ gross ratio section, $\mathrm{R} 2=$ natural rubber $40 \%$ gross ratio section) ( $\left.\mathrm{P}_{1} 3: \mathrm{R} 2\right)$, corresponding to Fig.1(b).

\section{Conclusions}

The crystallinity of PHBV blended films are characterized by x-ray diffractometry (XRD), which are existed their identity crystals $(2 \theta)$ at 13.30 and 16.68 degree. Natural rubber, however, specifies as amorphous materials with very broad peaks. Both the PHBV and freash natural rubber latex are mixed to improved some properties of PHBV, hard and brittle material. The maximum tensile modulus obtains for the $3 \% \mathrm{w} / \mathrm{v} \mathrm{PHBV}$ to-Natural rubber ratio $(6: 4$ or $3: 2)$. According to the mechanical testing, the results specify that the PHBV blendsare capable to develope their mechanical properties by more resilience. The assorted elastic moduli of $1 \%$, $2 \%$ and $3 \% \mathrm{w} / \mathrm{v}$ PHBV blends are identified in the average of 773,955 and $1,007 \mathrm{kPa}$, respectively. Elastic moduli of the blends increase with increasing the PHBV concentrationsimilarily to the tensile strengths. High crystallinities of $3 \% \mathrm{w} / \mathrm{v}$ PHBV mixtures obtain better tensile strength and tensile modulus. Thus, crystal structures of the mixtures relate to mechanical properties of materials. 

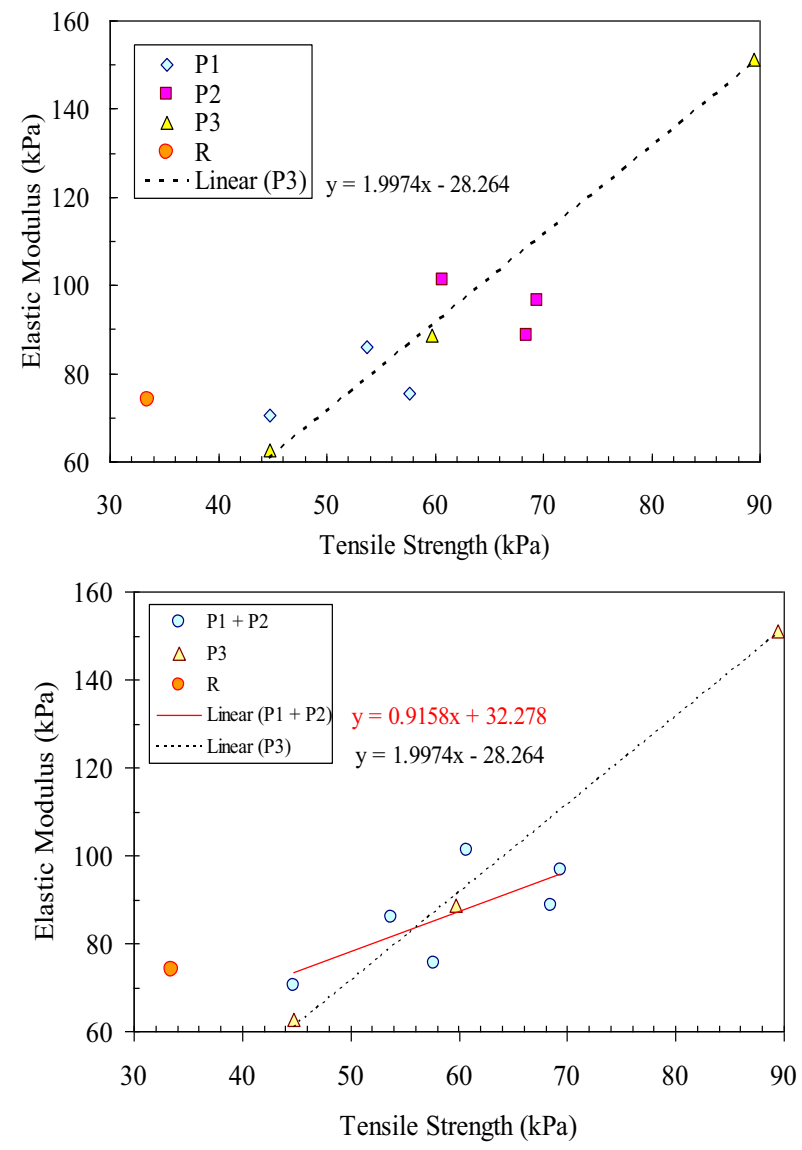

Figure 4. Elastic modulus as a function of yield strength of the blends.

\section{References}

1. V. Sridhar, I. Lee, H. H. Chun and H. Park: Express Polymer Letters Vol. 7 (2013), p. 320-328.

2. Y. X. Weng, Y. Wang, X. L. Wang and Y. Z. Wang: Polymer Testing Vol. 29 (2010), p. 579-587.

3. J. F. J. Coelho, J. R. Góis, A. C. Fonseca and M. H. Gil: Journal of Applied Polymer Science Vol. 116 (2009), p. 718-726.

4. K. Kuntanoo, S. Promkotra and P. Kaewkannetra: Key Engineering Materials Vol. 659 (2015), p. 404408.

5. K. Kuntanoo, S. Promkotra and P. Kaewkannetra: AIP Conference Proceedings Vol. 1653, (2015), p.020063-1-020063-8.

6. S. Nara and T. Komiya: Starch-Starke, Vol 35 (1983), p. 407.

7. P. Kaewkannetra and S. Promkotra: Defect and Diffusion Forum Vol. 312-315 (2011), p. 688-693.

8. P. Kaewkannetra and S. Promkotra: Defect and Diffusion Forum Vol. 334-335 (2013), p. 49-54. 